\title{
Fitoquímica e Alelopatia da Aroeira -Vermelha (Schinus terebinthifolius Raddi) na Germinação de Sementes
}

\section{Phytochemistry and Allelopathy of Aroeira Vermelha (Schinus terebinthifolius Raddi) in Seed Germination}

\author{
Gislayne de Araujo Bitencourta; Cibele Caren Moraes Gonçalves ${ }^{\mathrm{a}}$; Artur Guerra Rosa ${ }^{\mathrm{a}}$; Deizeluci de Fátima Pereira \\ Zanella $^{\mathrm{a}}$; Rosemary Matias ${ }^{\mathrm{b}}$
}

\begin{abstract}
anniversidade Estadual de Mato Grosso do Sul, Unidade Universitária de Aquidauana. MS, Brasil.

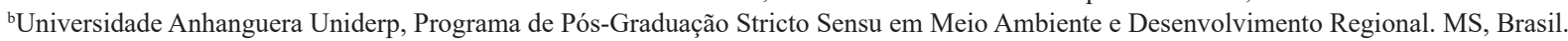

*E-mail: rosematias@anhanguera.com
\end{abstract}

\begin{abstract}
Resumo
Os compostos alelopáticos podem afetar o crescimento e inibir a germinação das espécies. O objetivo deste trabalho foi analisar a fitoquímica e o efeito alelopático do extrato das folhas de Schinus terebinthifolius Raddi na germinação e crescimento de plântulas de Lactuca sativa L. e, posteriormente, aplicar a metodologia em eucalipto vermelho (Eucalyptus camaldulensis). Os compostos químicos foram determinados em extrato alcoólico das folhas, comparados e contrastados observando a alteração de cor. As sementes de alface e eucalipto vermelho foram distribuídas em gerbox contendo papel filtro como substrato, umedecido com $7 \mathrm{~mL}$ do extrato aquoso das folhas frescas, nas seguintes concen trações: $(0 ; 12,5 ; 25 ; 50 ; 75$ e 100\%). Para todas as análises e experimentos foram utilizados três repetições. Os gerbox foram distribuídos em um delineamento inteiramente casualizado, mantidos em câmara de germinação com temperatura de $20^{\circ} \mathrm{C}$ para alface e $28^{\circ} \mathrm{C}$ para eucalipto e fotoperíodo de 12 horas. Durante o segundo e quinto dia foram realizadas contagens das sementes germinadas de alface. O período de avaliação do experimento foi de cinco dias para alface e 12 dias para eucalipto. Ao final, foram determinadas as porcentagens de germinação, comprimento da raiz e de parte aérea das plântulas. Os resultados demonstraram interferência negativa na germinação e crescimento de alface e eucalipto em função do aumento da concentração do extrato. Entre os aleloquímicos predominantes estão os compostos fenólicos e derivados, com destaque aos flavonoides, terpenos e heterosídeos cardioativos o que pode estar relacionados ao efeito alelopático negativo da aroeira. O uso da aroeira associado ao eucalipto deve ser feito com um manejo adequado.
\end{abstract}

Palavras-chave: Alface. Aleloquímicos. Anacardiaceae. Eucalipto. Efeito Alelopático.

\begin{abstract}
Allelopathic compounds can affect growth and inhibit species germination. The objective of this work was to analyze the phytochemistry and the allelopathic effect of extract of Schinus terebinthifolius Raddi leaves on the Lactuca sativa L. seedlings germination and growth and later apply the methodology in red eucalyptus (Eucalyptus camaldulensis). The chemical compounds were determined in the leaves alcoholic extract, compared and contrasted observing the color change. The lettuce and red eucalyptus seeds were distributed in a gearbox containing filter paper as a substrate, moistened with $7 \mathrm{~mL}$ of the fresh leaves aqueous extract in the following concentrations: $(0 ; 12.5 ; 25 ; 50 ; 75$ and $100 \%)$. For all analyzes and experiments, three repetitions were used. The gearbox was distributed in a completely randomized design, maintained in a germination chamber with a temperature of $20^{\circ} \mathrm{C}$ for lettuce and $28{ }^{\circ} \mathrm{C}$ for eucalyptus and a photoperiod of 12 hours. Germinated lettuce seeds were counted during the second and fifth days. The experiment evaluation period was five days for lettuce and 12 days for eucalyptus. At the end, the germination percentages, root length and the seedlings aerial part were determined. The results showed negative interference in the germination and growth of lettuce and eucalyptus due to the extract increased concentration. The most frequent allelochemicals were flavonoids, terpenes, tannins, anthocyanins and heterosides, which are probably related to the negative allelopathic effect. The use of aroeira associated with eucalyptus must be done with proper management.
\end{abstract}

Keywords: Lettuce, Allelochemicals Anacardiaceae. Eucalyptus. Allelopathic Effect.

\section{Introdução}

A espécie Schinus terebinthifolius Raddi. é popularmente conhecida como aroeira vermelha, aroeira mansa, aroeira brasileira, pertencente à família Anacardiaceae, é uma espécie nativa do Brasil, com ampla distribuição geográfica ocorrendo em diferentes formações florestais e, em vários habitats em função de sua tolerância e rusticidade a condições ambientais adversas e a dispersão dos frutos. Ainda, a espécie pode ser recomendada, para a recuperação de áreas degradadas, marginais e bordas de mata, em decorrência de sua resistência (CARLINI et al., 2010; OLIVEIRA JÚNIOR et al., 2013;
TRIGUEIRO; GUERRINI, 2014).

As plantas consideradas medicinais produzem vários metabólitos primários e secundários, que podem ter propriedades alelopáticas (MATSUMOTO et al., 2010). De acordo com Souza et al. (2007), Comiotto et al. (2011) e Bündchen et al. (2015), a aroeira apresenta potencial alelopático, em estudos realizados com alface, os autores relataram a redução na porcentagem de germinação e de crescimento das plântulas mediante a aplicação do extrato foliar.

Os efeitos alelopáticos podem variar quanto sua 
intensidade, fatores como quantidade, período de liberação e tempo de permanência interferem no comportamento dessas substâncias, além disso, o solo, a concentração, a temperatura e as condições hídricas são fatores que devem ser considerados para que os efeitos sejam persistentes (WANDSCHEER; BORELLA JUNIOR; CASSOL, 2009).

Entre os inúmeros fatores que agregam a importância aos estudos sobre a alelopatia, é justificado pela necessidade de substituição de insumos químicos por produtos naturais, além da necessidade do conhecimento relacionado às relações interespecíficas químicas e biológicas dos vegetais, visando solucionar problemas na produtividade de plantas cultivadas, regeneração de florestas, recuperação de áreas degradadas, consorciação de espécies, entre outros (MALHEIROS et al., 2014).

Existem várias metodologias para a avaliação da atividade alelopática e se utiliza o extrato das folhas em diversas concentrações em bioensaios de germinação com a alface (Lactuca sativa L.), que é uma espécie de rápida germinação, bastante sensível à presença de substâncias, possui crescimento linear insensível às diferenças de $\mathrm{pH}$ em ampla faixa de variação e insensibilidade aos potenciais osmóticos das soluções. Além de ser padronizada, internacionalmente, por normas como planta bioindicadora (GONÇALVES et al., 2016; TUR et al., 2010; GUSMAN et al., 2011).

Baseado no exposto acima se objetivou analisar a fitoquímica e o efeito alelopático do extrato das folhas de Schinus terebinthifolius Raddi na germinação e crescimento de plântulas de Lactuca sativa L. e, posteriormente, aplicar a metodologia em eucalipto vermelho (Eucalyptus camaldulensis Dehn.).

\section{Material e Métodos}

\subsection{Caracterização do extrato de aroeira}

As folhas novas e maduras da aroeira (S. terebinthifolius) foram coletadas de três matrizes localizadas na Universidade Estadual de Mato Grosso do Sul - UEMS, Unidade Universitária de Aquidauana - MS.

A análise fitoquímica foi realizada no Laboratório de Química da Uniderp. Para avaliar os fitoconstituintes de $S$. terebinthifolius foi obtido o extrato etanólico das folhas secas em estufa a $45^{\circ} \mathrm{C}$ por 72 horas, foram triturados em moinho e o pó extraído com etanol $(99,5 \%)$, em banho de ultrassom durante 60 minutos, seguido de maceração estática. A solução resultante foi filtrada e o solvente evaporado. Repetiu-se o procedimento por três dias para uma melhor extração, obtendo-se os extratos etanólicos bruto.

A caraterização fitoquímica do extrato ocorreu seguindo a metodologia adaptada de Matos (2009) e os resultados das análises foram comparados e contrastados observando a alteração de cor e precipitação com o teste em branco (apenas com etanol) e as intensidades das cores foram classificadas como base em Fontoura et al. (2015), considerando: 0\% frequência negativa $(0 \%), 5 \%$ frequência positiva baixa $(+/-$ ), $10 \%$ frequência positiva leve $(+), 25 \%$ frequência positiva moderada $(++/-), 50 \%$ frequência positiva parcial $(++), 75 \%$ frequência positiva alta $(+++/-), 100 \%$ frequência fortemente positiva $(+++)$.

Para a confirmação dos fenóis e derivados foram utilizados $10 \mathrm{mg}$ do extrato bruto seco das folhas dissolvidos em metanol $(99,5 \%)$ e completado volume para $25 \mathrm{~mL}$, em balão volumétrico. As absorbâncias foram medidas utilizando espectrofotômetro, em cubeta de quartzo, nos comprimentos de onda de 150 a $750 \mathrm{~nm}$, com três repetições (SILVERSTEIN et al., 2005).

O extrato etanólico foi utilizado para quantificar os fenóis totais (método Folin-Ciocalteu), utilizando como padrão o ácido gálico (10 a $350 \mathrm{mg} \mathrm{mL}^{-1}$ ), por meio de curva de calibração ( $\left.\mathrm{y}=0,781 \mathrm{x}-0,0031 ; \mathrm{R}^{2}=0,9959\right)$ (SOUSA et al., 2007). Para determinação dos flavonoides totais se utilizou o método cloreto de alumínio e como padrão a quercetina ( $\mathrm{y}=$ $0,132 \mathrm{x}+0,0353 \mathrm{R}^{2}=0,9949$ ) (PEIXOTO SOBRINHO et al., 2008).

O delineamento experimental dos fenóis e flavonoides totais foi realizado com três repetições para cada concentração e o cálculo das médias foi acompanhado do desvio padrão.

$\mathrm{O}$ extrato etanólico foi submetido às análises de $\mathrm{pH}$, condutividade elétrica (CE) e concentração de sólidos solúveis, determinada utilizando-se um refractômetro digital, com resultados expressos em graus Brix corrigidos para $20^{\circ} \mathrm{C}$.

\subsection{Ensaios de germinação}

Os ensaios de alelopatia foram desenvolvidos no laboratório de Fitossanidade da UEMS.

Os testes de germinação foram baseados na Regras para Análises de Sementes - RAS (BRASIL, 2009). As folhas de aroeira foram lavadas em água e trituradas no liquidificador, diluídas em água deionizada na proporção de 1:4. A solução foi agitada durante duas horas em mesa agitadora e coada em coador de pano.

$\mathrm{O} \mathrm{pH}$ e a condutividade do extrato aquoso foi medido utilizando um pHmetro e o condutivimetro, conforme metodologia de Salisbury e Ross (1992).

Foram realizados dois experimentos, um com sementes de L. sativa cv. aurélia e outro com as sementes de E. camaldulensis cv. LCF 014. As sementes foram distribuídas em caixa gerbox contendo papel filtro como substrato, umedecido com $7 \mathrm{~mL}$ do extrato diluído em água nas seguintes concentrações: 0 ; 12,$5 ; 25 ; 50 ; 75$ e $100 \%$.

As sementes de alface foram distribuídas em duas fileiras de 10 , totalizando 20 sementes com três repetições para cada tratamento, distribuídas em um delineamento inteiramente casualizado, mantidas em câmara de germinação do tipo BOD com temperatura de $20 \pm 2^{\circ} \mathrm{C}$ e fotoperíodo de 12 horas, por um período de cinco dias. Foram realizadas contagens no segundo e quinto dia, para obtenção da porcentagem de 
sementes germinadas.

A medição da parte aérea e da raiz de todas as plântulas normais foi feita com auxílio de um paquímetro digital e os resultados foram transformados em $\mathrm{cm}$.

Para as sementes de E. camaldulensis se utilizou a metodologia por meio de pesagem das sementes, conforme proposto pela RAS (BRASIL, 2009), em função da baixa taxa de pureza das mesmas, pois em muitas espécies é impossível diferenciar com segurança a semente dos óvulos não fertilizados ou os que não se desenvolveram em uma semente madura, nesse caso se utiliza o teste de sementes por repetições pesadas.

Utilizou-se $0,10 \mathrm{~g}$ de sementes de E. camaldulensis em cada gerbox, distribuídas em três fileiras, com três repetições para cada tratamento. As caixas foram distribuídas em delineamento inteiramente casualizado, mantidas em câmara de crescimento do tipo BOD, com temperatura controlada 28 $\pm 2{ }^{\circ} \mathrm{C}$ e fotoperíodo de 12 horas, por um período de 12 dias.

Ao final dos experimentos foram determinadas as porcentagens de germinação, comprimento de raiz e de parte aérea das plântulas.

Os dados obtidos para as duas espécies foram submetidos, separadamente, à análise de variância e regressão utilizando o software R (R CORE TEAM, 2014) e quando significativa foram selecionados os modelos com maior $\mathrm{R}^{2}$.

\section{Resultados e Discussão}

\subsection{Análise fitoquímica do extrato}

A análise do extrato etanólico de aroeira apresentou o $\mathrm{pH}$ tendendo a alcalinidade $(6,42 \pm 0,06)$; a condutividade elétrica foi baixa $\left(18,34 \pm 0,40 \mu \mathrm{S} \mathrm{cm}^{-1}\right)$ e os sólidos solúveis foram de $0,8 \%$, confirmando a baixa frequências dos açúcares redutores. Na Figura 1 estão apresentadas as frequências das classes de metabólitos secundários detectadas no extrato etanólico das folhas de aroeira.

Figura 1 - Frequência das classes de metabólitos secundários do extrato etanólico, das folhas de aroeira $(\mathrm{CF}=$ compostos fenólicos, $\mathrm{TE}=$ terpenos; $\mathrm{TA}=$ taninos, $\mathrm{FLA}=$ flavonoides, $\mathrm{CU}=$ cumarinas, $\mathrm{ANTRA}=$ antraquinonas, $\mathrm{TRIP}=$ triterpenos, $\mathrm{EST}=$ esteroides, $\mathrm{HC}=$ heterosídeos cardioativos, $\mathrm{AR}=$ açúcares redutores)

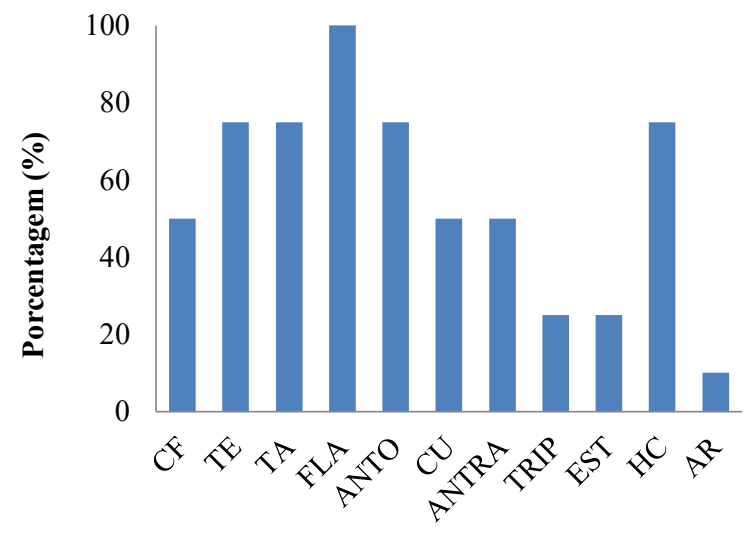

Metabólitos secundários
Os metabólitos secundários apresentam grande importância no mecanismo de defesa das plantas, principalmente, contra a herbivoria e outras defesas interespécies. As classes de metabólitos secundários detectados neste estudo (compostos fenólicos, flavonoides, taninos), são citados para outras espécies da família Anacardiaceae (BESSA et al., 2013).

A família Anacardiaceae apresenta altas concentrações de flavonoides, terpenos, esteroides, xantonas e, principalmente, dos lipídios fenólicos e derivados. Dentre os flavonoides, os bioflavonoides são os mais frequentes (CHAVES et al., 2010).

$\mathrm{Na}$ análise química do extrato observou a predominância em $100 \%$ do grupo de flavonoides. De acordo com Agati e Tattini (2010), os flavonoides têm a função de pigmentação, atração ou repelência a herbívoros, ações antimicrobianas, interferência na germinação de tubo de pólen, proteção contra radiação UV, influência no transporte de auxinas, captura espécies reativas de oxigênio e têm efeitos alelopáticos, podendo inibir o crescimento das plantas.

Bertoldi et al. (2009) identificaram que os flavonoides exerceram atividade alelopática em Avena sativa (Poaceae) inibindo a germinação de sementes de L. sativa.

Foi verificada a frequência de $75 \%$ de taninos, antocianinas e heterosídeos no extrato etanólico da aroeira. A aroeira vermelha é conhecida como planta tanífera, essa designação é feita a partir de sua composição química, que é rica em taninos e óleos essenciais (SANTANA et al., 2012).

Ceruks et al. (2007) citam a presença de terpenoides e ácidos graxos em $S$. molle e em S. terebinthifolius. Os terpenos apresentaram frequência de $75 \%$. De acordo com Willis (2010), os terpenos são capazes de lesionar tecidos de plantas.

Os teores de fenóis totais foram de 198,78 $\pm 0,99 \mathrm{mg}$ de equivalentes de ácido gálico/g e de flavonoides de 145,34 \pm $1,02 \mathrm{mg}$ de equivalentes de quercetina/g.

Os compostos fenólicos, com frequência de 50\% no extrato analisado, são citados como compostos com atividade alelopática (PEREIRA et al., 2018).

Os efeitos alelopáticos também podem ser mediados pela presença das cumarinas, com frequência de 50\% no extrato etanólico da aroeira, esses compostos são apontados como inibidores potentes do crescimento de plantas e germinação de sementes (WILLIS, 2010).

De acordo com Ripardo Filho et al. (2012) os esteroides apresentam atividade alelopática, observado na espécie Moutabea guianensis (Polygalaceae). No extrato da aroeira, os esteroides foram quantificados em 25\% apresentando-se em baixa concentração.

Os metabólitos mais citados na literatura, que estão presentes em $S$. terebinthifolius, são: o schinol, ácido masticadienóico, substâncias como a terebinthona, o ácido hidroximasticadienoico, o ácido terebintifólico e o ácido ursólico (CARVALHO et al., 2009; SANTANA et al., 2012).

\subsection{Ensaios de germinação}

A análise de $\mathrm{pH}$ das concentrações do extrato aquoso da

Fonte: Dados da pesquisa. 
aroeira utilizado nos ensaios de germinação, apresentou baixa variação e alta acidez, estando os valores entre 4,09 a 3,66. A condutividade elétrica variou de 345,9 a $1590 \mu \mathrm{S} / \mathrm{cm}^{-1}$ para as diferentes diluições realizadas com o extrato (Quadro 1).

Quadro 1 - Potencial hidrogeniônico $(\mathrm{pH})$ e condutividade elétrica (CE) do extrato aquoso de folhas de aroeira (Schinus terebinthifolius Raddi.) em diferentes concentrações

\begin{tabular}{|c|c|c|}
\hline Concentração (\%) & $\mathbf{p H}$ & $\mathbf{C E}\left(\boldsymbol{\mu S} / \mathbf{c m}^{-1}\right)$ \\
\hline 0 & 6,16 & 4,00 \\
12,5 & 4,09 & 345,4 \\
\hline 25 & 4,05 & 640,4 \\
\hline 50 & 4,02 & 1125 \\
\hline 75 & 3,99 & 1669 \\
\hline 100 & 3,66 & 1590 \\
\hline
\end{tabular}

Nota: Concentração $0 \%$ constituída de água deionizada.

Fonte: Dados da pesquisa.

Observa-se que na medida em que aumentam as concentrações do extrato de aroeira, o pH diminui e, consequentemente, aumenta a condutividade elétrica, esses parâmetros são considerados essenciais na determinação dos efeitos da alelopatia.

Segundo Silveira et al. (2012), a avaliação do pH é muito importante quando se desconhece a constituição química de uma solução, pois valores elevados de acidez podem atuar negativamente na inibição da germinação de sementes e no crescimento de plântulas.

$\mathrm{O}$ controle do $\mathrm{pH}$ e da concentração de extratos brutos devem ser monitorados, pois substâncias como açúcares, aminoácidos, ácidos orgânicos, entre outros, que podem mascarar os efeitos alelopáticos por influenciarem na concentração iônica e ser osmoticamente ativos, alterando a propriedade da água resultando em uma pressão osmótica diferente de zero na solução (TUR et al., 2010).

Entre os parâmetros utilizados para avaliar o vigor de sementes, encontra-se a avaliação da condutividade elétrica. Esse parâmetro está relacionado ao avanço do processo de deterioração das sementes, a alta condutividade elétrica promove a perda na integridade no sistema de membranas da célula, aumentando a permeabilidade e, consequentemente, a perda de eletrólitos para o meio, ocasionado um estresse hídrico (SOARES et al., 2010).

De acordo com Rabbani et al. (2013), o excesso de sais na solução provoca uma redução no potencial hídrico, reduzindo a capacidade de absorção de água pelas sementes, afetando a velocidade e o tempo. Fato esse que pode ser observado na avaliação da porcentagem de germinação das sementes de alface.

Foram obtidas diferenças significativas na germinação de sementes em função ao aumento da concentração do extrato. $\mathrm{Na}$ primeira contagem (segundo dia) nas concentrações de 50 a 100\% ocorreu decréscimo na porcentagem (Figura 2).
Figura 2 - Porcentagem de germinação (2 dias) de Lactuca sativa submetida em diferentes concentrações de extrato de aroeira

2 dias

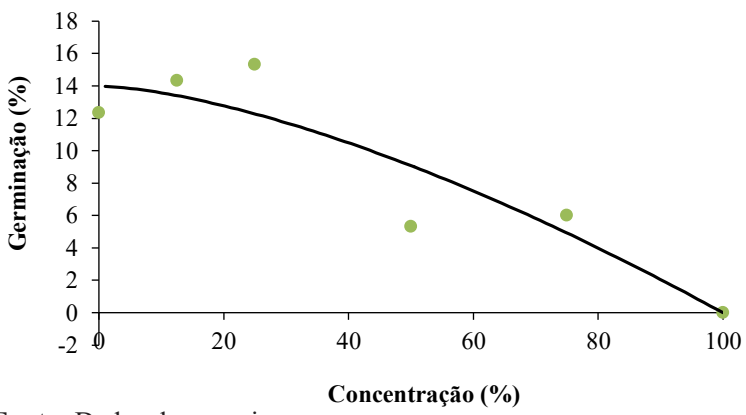

Fonte: Dados da pesquisa.

$\mathrm{Na}$ segunda contagem (quinto dia) na concentração de $100 \%$ ocorreu redução significativa na porcentagem de germinação, sugerindo um efeito alelopático negativo sobre as sementes (Figura 3).

Figura 3 - Porcentagem de germinação (5 dias) de Lactuca sativa submetida em diferentes concentrações de extrato de aroeira

\section{5 dias}

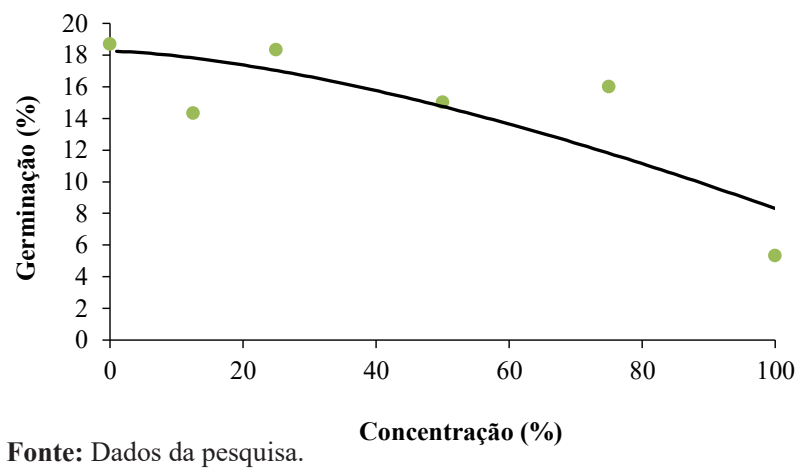

A porcentagem de germinação foi afetada durante os dois períodos de avaliação, diferente do observado por Gonçalves et al. (2016), que os efeitos alelopáticos não foram observados na germinalidade de alface.

Borella et al. (2009) verificaram que extratos de Schinus mole e Solanum americanum causaram efeitos inibitórios à germinação de sementes de rabanete, fato esse que evidencia redução da expressão do vigor das sementes, em função do efeito tóxico dos extratos.

Segundo Oliveira et al. (2012), o extrato de sementes de mulungu reduziu a germinação de sementes da alface cv. Mônica.

Existem alguns relatos na literatura que a alface apresenta ampla tolerância as variações de $\mathrm{pH}$ para germinação, com valores de 3,0 a 7,0 (MAIA et al., 2013; OLIVEIRA et al., 2014; GONÇALVES et al., 2016).

Oliveira et al. (2011), utilizando o extrato foliar de Rheedia brasiliensis na germinação de alface, verificaram efeito negativo a partir de $20 \%$. Outros autores, como Silva et al. (2010) utilizando os extratos etanólicos de Anadenanthera macrocarpa e Astronium graveolens ocasionaram efeitos negativos na germinação de Brassica chinensis (couve) e $L$. 
sativa, independente da concentração utilizada.

Analisando a variável de crescimento de parte aérea de L. sativa, o extrato promoveu interferência em função do aumento da concentração. Sendo que, a concentração de $100 \%$ foi a mais afetada, sugerindo que o extrato retardou crescimento das plântulas comparado ao controle (Figura 4).

Figura 4 - Comprimento de parte aérea (CPA) de Lactuca sativa submetida a diferentes concentrações de extrato de aroeira.

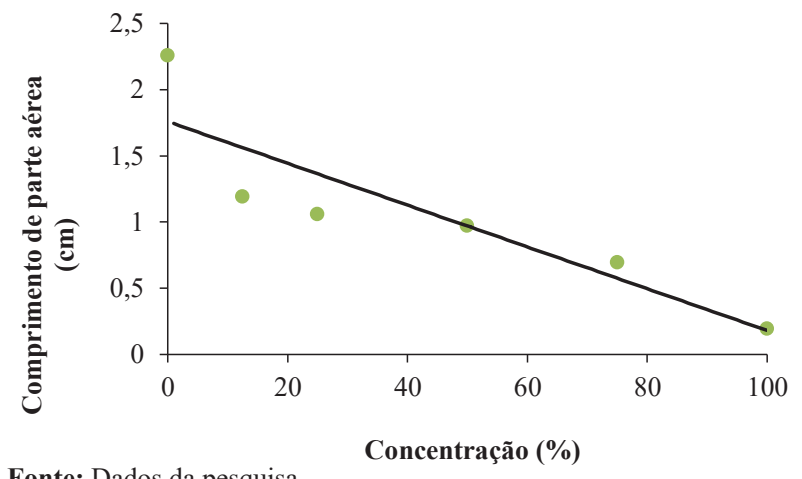

Fonte: Dados da pesquisa.

O mesmo foi verificado no comprimento das raízes, à medida que houve o aumento da concentração ocorreu redução no crescimento da raiz, enquadrando-se em um modelo de regressão linear (Figura 5).

Figura 5 - Comprimento de raiz (CR) de Lactuca sativa submetida a diferentes concentrações de extrato de aroeira

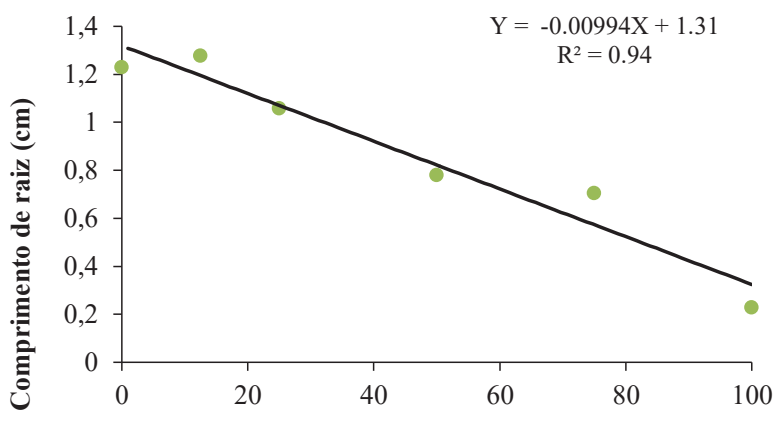

Fonte: Dados da pesquisa.

Concentração (\%)

Os resultados sugerem que a aplicação do extrato interferiu na germinação e crescimento inicial de alface. No presente estudo, os efeitos nas variáveis CR e CPA foram acompanhados por alterações morfológicas nas raízes, entre as quais se inclui ausência de pelos absorventes, redução e ausência da zona de crescimento e necrose. Além disso, a proliferação de fungos foi observada em função do aumento da concentração do extrato, confirmando a hipótese de que a aroeira apresenta compostos metabólicos alelopáticos negativos contidos em suas folhas.

A germinação e o crescimento de plântulas estão, frequentemente, associados aos efeitos alelopáticos. Comiotto et al. (2011) verificaram que extratos aquosos de $S$. terebinthifolius, proporcionaram redução da massa fresca de plântulas de alface com o aumento das concentrações.

Outros estudos realizados com extratos de outras espécies vegetais, também relataram o efeito alelopático negativo sobre as plântulas de alface. O extrato de folhas de Persea americana também causou o mesmo efeito em plântulas de alface (BORELLA et al., 2009). Rickli et al. (2011) verificaram que o extrato de folhas frescas de Azadirachta indica L. inibiu o crescimento da raiz de alface nas concentrações testadas.

Resultados semelhantes foram verificados no ensaio de germinação utilizando sementes de eucalipto vermelho. Os dados referentes à contagem de sementes germinadas demonstraram efeito significativo com o aumento da concentração do extrato de aroeira. As concentrações acima de $50 \%$ promoveram a redução linear de sementes germinadas (Figura 6).

Figura 6 - Média de germinação de sementes de Eucaliptus camadulensis submetidos a diferentes concentrações de extrato de aroeira

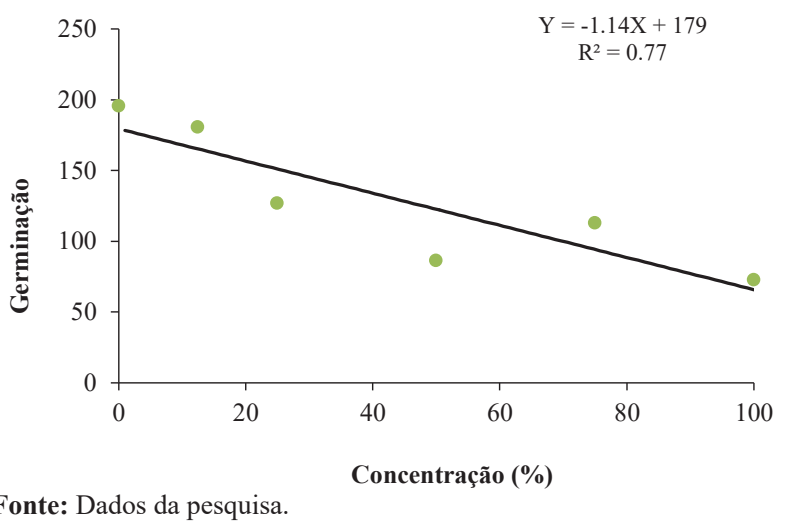

A variável comprimento de parte aérea pode ser explicada por um modelo polinomial de regressão de segundo grau, em que o efeito alelopático negativo foi mais evidente na concentração de 100\% (Figura 7).

Figura 7 - Comprimento de parte aérea (CPA) de Eucaliptus camadulensis submetidos a diferentes concentrações de extrato de aroeira

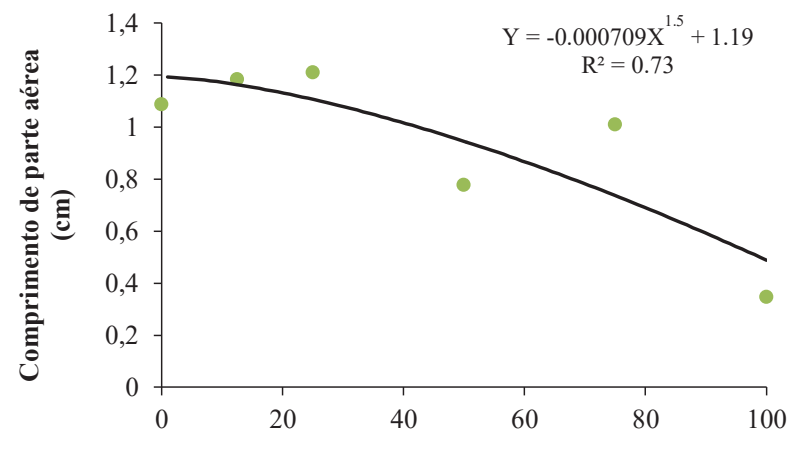

Concentração (\%)

Fonte: Dados da pesquisa.

Resultados semelhantes foram verificados para a variável comprimento de raiz que se enquadrou em um modelo linear com decréscimo em função do aumento da concentração do extrato de aroeira (Figura 8). 
Figura 8 - Comprimento de raiz (CR) de Eucaliptus camadulensis submetidos a diferentes concentrações de extrato de aroeira

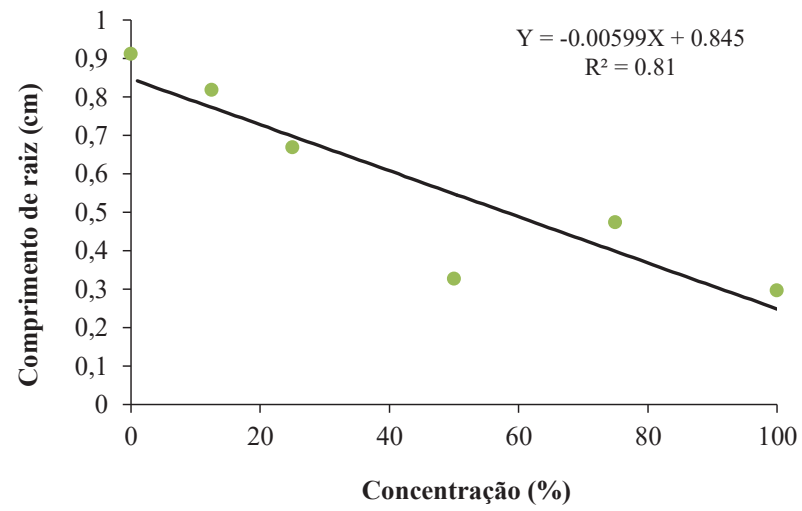

Fonte: Dados da pesquisa.

Neste contexto, foi possível detectar efeito alelopático dos extratos das folhas de $S$. terebinthifolius sobre a germinação, crescimento de raiz e parte aérea de alface e eucalipto. Esses resultados são compatíveis com as observações de Souza et al. (2007), Comiotto et al. (2011) e Bündchen et al. (2015).

Souza et al. (2007) avaliou os efeitos alelopáticos da aroeira utilizando o extrato aquoso das folhas frescas fervido e não fervido, os mesmos apresentaram diferença significativa na germinação de alface, ocasionando redução nessa variável, porém não foram citadas diferenças entre os tratamentos utilizados.

Comiotto et al. (2011) relatam os efeitos inibitórios do extrato aquoso das folhas de aroeira, que promoveram redução em todas as variáveis avaliadas, a partir da concentração de $50 \%$.

Bündchen et al. (2015) avaliaram a alelopatia de folhas e de frutos da aroeira, prepararam o extrato com água aquecida a $80^{\circ} \mathrm{C}$ e após o repouso, centrifugaram e utilizaram o sobrenadante no bioensaio. Os autores citam a inibição na germinação e produção de biomassa nas plântulas de alface tanto nas folhas quanto nos frutos.

A respeito dos efeitos alelopáticos da aroeira sobre a germinação e crescimento de E. camaldulensis, ainda são escassos. Porém, com o presente estudo foi possível observar que houve efeito significativo do extrato sobre a germinação das sementes, crescimento de parte aérea e de raiz, confirmando o efeito alelopático negativo de $S$. terebinthifolius.

Estes resultados estão relacionados à presença dos metabólitos secundários (Figura 1) detectados no extrato de S. terebinthifolius, anteriormente listados como potenciais aleloquímicos por vários autores (OLIVEIRA et al., 2014; BESSA et al., 2013; CHAVES et al., 2010; WILLIS, 2010). Com base na análise fitoquímica se sugere que o efeito alelopático esteja ligado à presença de flavonoides, terpenos, taninos, antocianinas e heterosídeos.

\section{Conclusão}

$\mathrm{O}$ extrato das folhas de aroeira nas concentrações de 50 a $100 \%$ apresentou efeitos alelopáticos negativos nas taxas de germinação, crescimento inicial e desenvolvimento de raiz de sementes de alface e de eucalipto, ocasionando anomalias morfológicas e proliferação de fungos.

Os metabólitos secundários, com maior frequência, foram os flavonoides, terpenos, taninos, antocianinas e heterosídeos, provavelmente, estejam relacionados ao efeito alelopático negativo.

\section{Referências}

AGATI, G.; TATTINI, M. Multiple functional roles of flavonoids in photoprotection. New Phytologist, v.186, n.4, p.786-790, 2010. doi: $10.1111 / \mathrm{j} .1469-8137.2010 .03269 . \mathrm{x}$

BERTOLDI, C.de. et al. Bioassay-guided isolation of allelochemicals from Avena sativa L.: allelopathic potential of flavone C-glycosides. Chemoecology, v.19, p.169-176, 2009. doi: 10.1007/s00049-009-0019-5

BESSA, N.G.F.de. et al. Prospecção fitoquímica preliminar de plantas nativas do cerrado de uso popular medicinal pela comunidade rural do assentamento vale verde - Tocantins. Revista Brasileira de Plantas Medicinais, v.15, n.4, p.692-707, 2013. doi:10.1590/S1516-05722013000500010.

BORELLA, J.; PASTORINI, L. H. Influência alelopática de Phytolacca dioica L. na germinação e crescimento inicial de tomate e picão-preto. Biotemas, v.22, n.3, p.67-75, 2009. doi: 10.5007/2175-7925.2009v22n3p67

BRASIL, Ministério da Agricultura e Reforma Agrária. Regras para análise de sementes. Brasília: MS, 2009.

BÜNDCHEN, M. et al. Extratos Aquosos de Schinus terebinthifolius Raddi inibem a Germinação e o Desenvolvimento Inicial de Lactuca sativa L. Scie. Tec, v.2, n.1, p.102-109, 2015.

CARLINI, E.A. et al. Antiulcer effect of the pepper trees Schinus terebinthifolius Raddi (aroeira-da-praia) and Myracrodruon urundeuva Allemão, Anacardiaceae (aroeira-do-sertão). Rev. Bras. Farm., v.20, n.2, p.140-146, 2010. doi:10.1590/S0102695X2010000200001

CARVALHO, M.G. et al. Determination of gallic acid in preparations derived from Schinus terebinthifolius Raddi. Chromatogr. Suppl., v.69, p.249-253, 2009. doi:10.1365/s10337009-1096-x

CERUKS, M. et al. Constituintes fenólicos polares de Schinus terebinthifolius RADDI (Anacardiaceae). Quim. Nova, v.30, n.3, p.597-599, 2007. doi: 10.1590/S0100-40422007000300018

CHAVES, M. H. et al. Fenóis totais, atividade antioxidante e constituintes químicos de extratos de Anacardium occidentale L., Anacardiaceae. Rev. Bras. Farm., v.20, p.106-112, $2010 . \quad$ doi: 10.1590/S0102-695X2010000100021.

COMIOTTO, A., MORAES, D.M., LOPES, N.F. Potencial alelopático de extratos aquosos de aroeira sobre germinação e crescimento de plântulas de alface. Scie. Agrar. Paranaensis, v.10, p.23-31, 2011. doi:10.18188/sap.v10i3.4349

FONTOURA, F. M. et al. Seasonal effects and antifungal activity from bark chemical constituents of Sterculia apetala (Malvaceae) at Pantanal of Miranda, Mato Grosso do Sul, Brazil. Acta Amazon., v.45, p.283-292, 2015.

GONÇALVES, V.D.; COELHO, M.F.de.B.; CAMILI, E.C. Bioensaios em sementes de Lactuca sativa L. com extrato de folhas de Kielmeyera coriácea Mart. \& Zucc. Rev Int. Ciênc., v.6, n.2, p.160-170, 2016. doi: 10.1590/1809-4392201500011

GUSMAN, G.S., YAMAGUSHI, M.Q., VESTENA, S. Potencial alelopático de extratos aquosos de Bidens pilosa L., Cyperus 
rotundus L. e Euphorbia hterophylla L. Iheringia, Série Bot., v.66, p.87-98, 2011.

MAIA, S.S.S. et al. Atividade biológica de extratos de espécies do Rio Grande do Norte em sementes de alface. Rev. Verde Agroecol. Desenvolv. Sustent., v.8, n.4, p.169-173, 2013.

MALHEIROS, R.S.P. et al. Atividade alelopática de extratos de Lafoensia pacari A. ST. -HIL. sobre Lactuca sativa L. e Zea mays L. em condições de laboratório. Rev. Bras. Agroecol., v.9, n.1, p.185-194, 2014.

MATOS, F. J. A. Introdução a fitoquímica experimental. Fortaleza: UFC, 2009.

MATSUMOTO, R.S. et al. Potencial alelopático do estrato foliar de Annona glaba L. (Annonaceae). Acta Bot. Bras., v.24, p.631635, 2010. doi: 10.1590/S0102-33062010000300005

OLIVEIRA JUNIOR, L.F.G. et al. Efeito fungitóxico do óleo essencial de aroeira da praia (Schinus terebinthifolius RADDI) sobre Colletotrichum gloeosporioides. Rev. Bras. Plantas Med., v.15, n.1, p.150-157, 2013. doi:10.1590/S151605722013000100021

OLIVEIRA, A.K.M. et al. Potencial alelopático de folhas frescas de bacupari (Rheedia brasiliensis (Mart.) Planch. \& Triana) na germinação de alface. Rev. Bras. Bioc., v.9, p.550-553, 2011.

OLIVEIRA, A.K. et al. Alelopatia de extratos de diferentes órgãos de mulungu na germinação de alface. Horticultura Bras., v.30, p.480-483, 2012. doi:10.1590/S0102-05362012000300020.

OLIVEIRA, A.K.M. et al. Análise fitoquímica e potencial alelopático das cascas de Pouteria ramiflora na germinação de alface. Horticultura Bras., v.32, p.41-47, 2014. doi: 10.1590/ S0102-05362014000100007

PEIXOTO SOBRINHO, T.J.S. et al. Validação de metodologia espectrofotométrica para quantificação dos flavonóides de Bauhinia cheilantha (Bongard) Steudel. Rev. Bras. Ciênc. Farm., v.44, n.4, p.683-689, 2008. doi:10.1590/S151693322008000400015

PEREIRA, K.C.L. et al. Potencial alelopático do extrato etanólico de Anacardium humile A.St.-Hil. (cajuzinho-do-cerrado) na germinação e formação de plântulas de Lactuca sativa L. (alface), Lycopersicon esculentum Mill. (tomate) e Senna obtusifolia (L.) Irwin \& Barneby (fedegoso). Gaia Scie., v.12, n.2, p.144-160, 2018. doi: 10.22478/ufpb.1981-1268.2018v12n2.37091

R CORE TEAM. $R$ : A language and environment for statistical computing. R Foundation for Statistical Computing, Vienna, Austria. 2014. Disponível em: $<$ http://www.R-project.org $>$.

RABBANI, A.R.C. et al. Efeito do estresse salino sobre atributos da germinação de sementes de girassol. Scie. Plena, v.9, n.5, p.16, 2013.

RICKLI, H.C. et al. Allelopathic effect of aqueous extract of Azadirachta indica A. Juss. on lettuce, soybeans, maize, beans and Bidens pilosa. Semina: Ciênc. Agrár., v.32, p.473-484, 2011. doi: 10.5433/1679-0359.2011v32n2p473

RIPARDO FILHO, H.S. et al. Bioensaios de atividade alelopática dos esteroides espinasterol, espinasterona e glicopiranosil espinasterol. Planta Daninha, v.30, n.4, p.705-712, 2012. doi: 10.1590/S0100-83582012000400003.

SALISBURY, F. B.; ROSS, C. Plant physiology. Wadsworth, Belmont, USA, 1992.

SANTANA, J. S, SARTORELLI, P., LAGO, J. H. G. Isolamento e avaliação do potencial citotóxico de derivados fenólicos de Schinus terebinthifolius Raddi (Anacardiaceae). Quím. Nova, v.35, p.2245-2248, 2012. doi: 10.1590/S0100-40422012001100029

SILVA, R.M.G. et al. Potencial alelopático de extrato etanólico de Anadenanthera macrocarpa e Astronium graveolens. Biosc. J., v.26, p.623-637, 2010.

SILVEIRA, P.F., MAIA, S.S.S., COELHO, M.F.B. Potencial alelopático do extrato aquoso de cascas de jurema preta no desenvolvimento inicial de alface. Rev. Caatinga, v.25, p.20-27, 2012.

SILVERSTEIN, R.M.; WEBSTER, F.X.; KIEMLE, D. Spectrometric identification of organic compounds. New York: Wiley, 2005.

SOARES, M.M. et al. Testes para avaliação do vigor de sementes de sorgo com ênfase à condutividade elétrica. Ciênc. Agrotecnol., v.34, n.2, p.391-397, 2010. doi:10.1590/S141370542010000200017.

SOUSA, C.M.M. et al. Fenóis totais e atividade antioxidante de cinco plantas medicinais. Quím. Nova, v.30, n.2, p.351-355. 2007. doi: 10.1590/S0100-40422007000200021

SOUZA, C.S.M.de. et al. Alelopatia do extrato aquoso de folhas de aroeira na germinação de sementes de alface. Rev. Verde, v.2, n.2, p.96-100, 2007.

TRIGUEIRO, R.M; GUERRINI, I.A. Utilização de lodo de esgoto na produção de mudas de aroeira-pimenteira. Rev. Árvore, v.38, n.4, p.657-665, 2014.

TUR, C.M., BORELLA, J., PASTORINI, L.H. Alelopatia de extratos aquosos de Duranta repens sobre a germinação e crescimento inicial de Lactuca sativa e Lycopersicum esculentum. Rev. Biotemas, v.2, p.13-22, $2010 . \quad$ doi: 10.5007/2175-7925.2010v23n2p13

WANDSCHEER, A.C.D.; BORELLA JUNIOR, B.L.; CASSOL, P.L.H. Atividade alelopática de folhas e pseudofrutos de Hovenia dulcis Thunb. (Rhamnaceae) sobre a germinação de Lactuca sativa L. (Asteraceae). Acta Bot. Bas., v.25, n.1, p.25-30, 2011. doi: 10.1590/S0102-33062011000100005.

WILLIS RJ. The history of allelopathy. New York: Springer Verlag, 2010. 